\title{
The use of the Modified Early Obstetric Warning System (MEOWS) in women after pregnancies: a descriptive study
}

Luciana Schuler 1

https://orcid.org/0000-0002-8760-5250

Leila Katz 2

https://orcid.org/0000-0001-9854-7917

Brena Carvalho Pinto de Melo 3

https://orcid.org/0000-0002-7671-2122

Isabela C. Coutinho 4

iD https://orcid.org/0000-0003-4707-4069

\footnotetext{
1-4 Instituto de Medicina Integral Prof. Fernando Figueira. Rua dos Coelhos, 300. Boa Vista. Recife, PE, Brazil. CEP: 50.070-902. E-mail: isabelacoutinhoneiva@gmail.com
}

\begin{abstract}
Objectives: to evaluate the modified early obstetric warning system (MEOWS) in women after pregnancies in a tertiary hospital in Brazil.

Methods: a descriptive study was conducted with 705 hospitalized women. Vital signs (systolic and diastolic blood pressure, heart rate, respiratory rate, temperature) and lochia were registered on medical records and transcribed into the MEOWS chart of physiological parameters. On this graphic chart, yellow alerts were used to present moderate abnormalities in vital signs, while severe abnormalities were presented in red. The presence of at least one red alert or two yellow alerts were triggered to indicate the need for medical evaluation.

Results: although abnormalities were found in the physiological parameters of $49.8 \%$ of the women identified from MEOWS triggers, medical evaluation was only requested for three patients $(0.8 \%)$

Conclusions: in a retrospective application of the use of MEOWS showed a significant number of patients had triggered in which the nursing team did not recognize $99.2 \%$ of cases. This finding could be attributed to the fact that MEOWS has not been yet adopted in this service as part of the nursing care. The application of this tool would result in a better care because critical situations would be recognized and corrected quickly, avoiding unfavorable outcomes.

Key words Women, Pregnancy, Morbidity
\end{abstract}

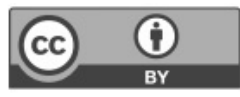




\section{Introduction}

The high maternal morbidity and mortality rates constitute one of major concern worldwide. 1 Maternal mortality has been described as "the tip of the iceberg" while its base corresponds to the overall morbidity which occurs in women due to health problems associated with pregnancy and postpartum. ${ }^{2}$ For every woman who dies from pregnancy-related causes, another 20-30 women suffer the effects of acute or chronic morbidity causing permanent sequelae. ${ }^{3}$

From a conceptual point of view, there is a spectrum of clinical severity with healthy pregnancy at one extreme and maternal death at another. Within this continuum, there is a degree of severe morbidity that corresponds to the concept of maternal near miss. ${ }^{4}$ Severe acute maternal morbidity and maternal near miss are two terms commonly used as synonymous for severe, life-threatening obstetric complications. 5 Since maternal near miss is considered a better reflection of a woman's concept of who "almost died but survived", the World Health Organization (WHO) recommends the use of the term "maternal near miss" rather than severe acute maternal morbidity. 5

In patients who developed severe morbidity or who died, it is often found that there was a period of slow and progressive physiological deterioration that went unnoticed and/or was treated inappropriately.68 Therefore, in 1997, the first early warning system was developed in the United Kingdom based on abnormalities in the patient's physiological parameters. ${ }^{8}$ The objective of this early warning system (EWS), was developed for the non-obstetric adult population, and was to enable patients with risk of complication to be identified as early as possible. ${ }^{8}$ According to those authors, abnormalities in the physiological parameters were found up to eight hours prior to unfavorable events such as the need to be admitted to an intensive care unit (ICU) or the occurrence of cardiorespiratory arrest. ${ }^{8}$

Due to the physiological modifications observed at pregnancy, most authors affirm that early warning systems developed for the general adult population should not be used for pregnant and postpartum women.9-11 Since 2007, the United Kingdom validated and recommended the use of an early warning score adapted for the obstetric population - the Modified Early Obstetric Warning System (MEOWS). 10,12

Surveillance data on maternal deaths from various countries $13-15$ show that $40-50 \%$ of the deaths could have been avoided. Delays in recog- nizing, diagnosing and treating precede the majority of the deaths were resulting from hemorrhage, preeclampsia/eclampsia and infection. ${ }^{13-15}$ Most obstetric patients are young and healthy, and their response to pathological mechanisms is good; however, the physiological changes in vital signs that occur during pregnancy may make it difficult to recognize clinical decompensation at an early stage. Several entities such as the American College of Obstetrics and Gynecology, ${ }^{16}$ The Joint Commission 17 and The National Partnership in Women's Health, 18 as well as publications such as the Confidential Enquiries into Maternal and Child Health (CEMACH). ${ }^{10}$ recommend the use of early obstetric warning systems to improve maternal and perinatal outcomes.

In regard to maternal morbidity and mortality and the fact that no studies have been conducted on the use of MEOWS in Brazil, this present study proposed to describe the application of MEOWS and its capacity to enable patients with risk of complication to be identified at an early stage.

\section{Methods}

A descriptive study was carried out at the Instituto de Medicina Integral Prof. Fernando Figueira (IMIP), a tertiary hospital in the Northeast of Brazil, between November 2014 and May 2015. This was a non-probabilistic, convenience sample. The sample size was calculated using Epi Info, version 3.5.1, based on a trigger frequency of $30 \%$. For a relative precision of $15 \%$ and a confidence level of $99 \%$, a sample of 688 patients would be required. This number was increased to 750 patients to compensate for any loss on medical records or missing data.

This study included 705 women after they had given birth or were assisted due to abortions, had ectopic pregnancies or molar pregnancies at Instituto de Medicina Integral Prof. Fernando Figueira or at another healthcare institution but they were referred for admission at IMIP at he time of the study.

The main researcher and the research assistants visited the sectors four times a week, on random days and reviewed all the women's medical records that were discharged. The researchers applied a checklist on the medical records to confirm the inclusion and exclusion criteria, if positive, the explanations regarding to the objectives and the details of this study were given to the patient and/or to her family and afterwards, she would be invited to participate in the study. In case of an agreement, an informed consent form would be read and asked to be signed. Next, the checklist was filled out and if 
the patient fulfilled the eligibility criteria she would be included in the study. Patients with near miss criteria at admission and those whose vital signs had not been registered at admission were excluded from the study.

The study variables were: systolic blood pressure (SBP), diastolic blood pressure (DBP), heart rate (HR), respiratory rate (RR), temperature, lochia, the trigger frequency, the trigger frequency that generated calls for receiving medical care, time between the trigger and the call for receiving medical care, time between the trigger and the provision of medical care, the administration of prescribed "as needed" medication and events leading to the administration of prescribed "as needed" medication. The patients' sociodemographic and obstetric characte-ristics were also analyzed.

The system used was MEOWS (Figures 1 and 2), which is a simple tool used to screen for maternal morbidity that can be applied on any pregnant or postpartum patient. 9 It consists of the completion of a chart on physiological parameters which the following data are registered: respiratory rate, temperature, heart rate, systolic and diastolic blood pressure and lochia.9,10 This instrument presents abnormal values in red or yellow. 9 When a parameter is seen to be extremely abnormal (a red line) or a simultaneous combination of two abnormal parameters (yellow line), this is referred to as a "trigger" and which means that the nurse should call for a physician. ${ }^{9}$

The physiological parameters are considered moderately abnormal (yellow alerts) when the values are: SBP: $91-100$ or $151-160 \mathrm{mmHg}$, DBP: $91-100$ mmHg, HR: $41-50$ or $101-120$ beats per minute (BPM), RR: 21-30 breaths/minute, temperature 35$36^{\circ}$ Celsius $\left({ }^{\circ} \mathrm{C}\right)$ and if there is an increased amount of lochia or discharge of fetid lochia. Values considered extremely abnormal (red alerts) are: $\mathrm{SBP} \leq 90$ or $\geq 161 \mathrm{mmHg}, \mathrm{DBP} \geq 101 \mathrm{mmHg}, \mathrm{HR}<40$ or $>120$ bpm, RR $0-10$ or $>30$ breaths/minute, temperature $<35$ or $\geq 38.1{ }^{\circ} \mathrm{C} .9$

A pregnancy was classified as high risk if, at the moment of hospitalization and being discharged, maternal and/or fetal conditions that increased maternal or fetal risk were presented. Hypertension, diabetes, previous clinical diseases and abnormal placentation, and among others were also included as high-risk pregnancy.

Data analysis was conducted using Epi Info, version 7.1. The categorical variables are shown as frequency distributions. Measures of central tendency and dispersion were calculated for the numerical variables. Means and standard deviations
(SD) were used for the continuous numerical variables, whereas medians were used for discreet numerical variables.

The internal review board at IMIP acknowledged by the Research Ethics Committee (CONEP), approved this study under the reference number: CAEE 35903214.0.0000.5201. The patients who participated in this study signed an informed consent form. The professional assistants at IMIP were unaware of the study objectives. The study was carried out according to the Declaration of Helsinki, as reviewed in 2008 .

\section{Results}

A total of 705 women were included in the study. The sample included low-risk as well as high-risk patients. In the case of high-risk women, the reasons for hospitalization were documented. Forty-five patients were excluded from the study: 22 because the informed consent was not signed, 19 refused to participate, 1 was admitted with near miss criteria, and 3 because their vital signs had not been registered.

During the study period, a sample of 705 women after their pregnancies was selected and the characteristics of these women are shown in Table 1. The patients' age ranged from 11 to 45 years, with a mean of $25.9 \pm 6.9$ years. Of these women, $65.2 \%$ were classified as mixed; $69.3 \%$ had more than eight years of schooling; $65.7 \%$ were married or in a stable union; and $55.2 \%$ were homemaker.

Gestational age ranged from 5 to 44 weeks, with a mean of 37 weeks. Of these women, $33.8 \%$ had preterm pregnancy (under 37 weeks); $65.5 \%$ had term pregnancy (37-41 weeks); and $0.7 \%$ had post term pregnancy. Of the women in this sample, $42.3 \%$ were primigravidas; $47.3 \%$ had only one child; $56.2 \%$ had undergone natural childbirth; $83.3 \%$ were classified as high-risk; and $25.1 \%$ had clinical comorbidities (the most frequent were hypertension, heart disease and human immunodeficiency virusHIV/acquired immunodeficiency syndrome-AIDS) (Table 2).

The main reasons for hospitalization were hypertensive syndromes, responsible for $51.8 \%$ of admissions $(n=301)$, followed by fetal malformations (7.1\%), gestational diabetes $(5.8 \%)$ and premature of membranes $(5.7 \%)$

Median systolic blood pressure was $120.0 \pm 17.2$ $\mathrm{mmHg}$ (range $60-200 \mathrm{mmHg}$ ) and median diastolic blood pressure was $80.0 \pm 13.6 \mathrm{mmHg}$ (range 40 $120 \mathrm{mmHg}$ ). Median heart rate was $81.5 \pm 12.2 \mathrm{bpm}$ (range 51-144 bpm) and median respiratory rate was 
Figure 1

MEOWS graphic chart.

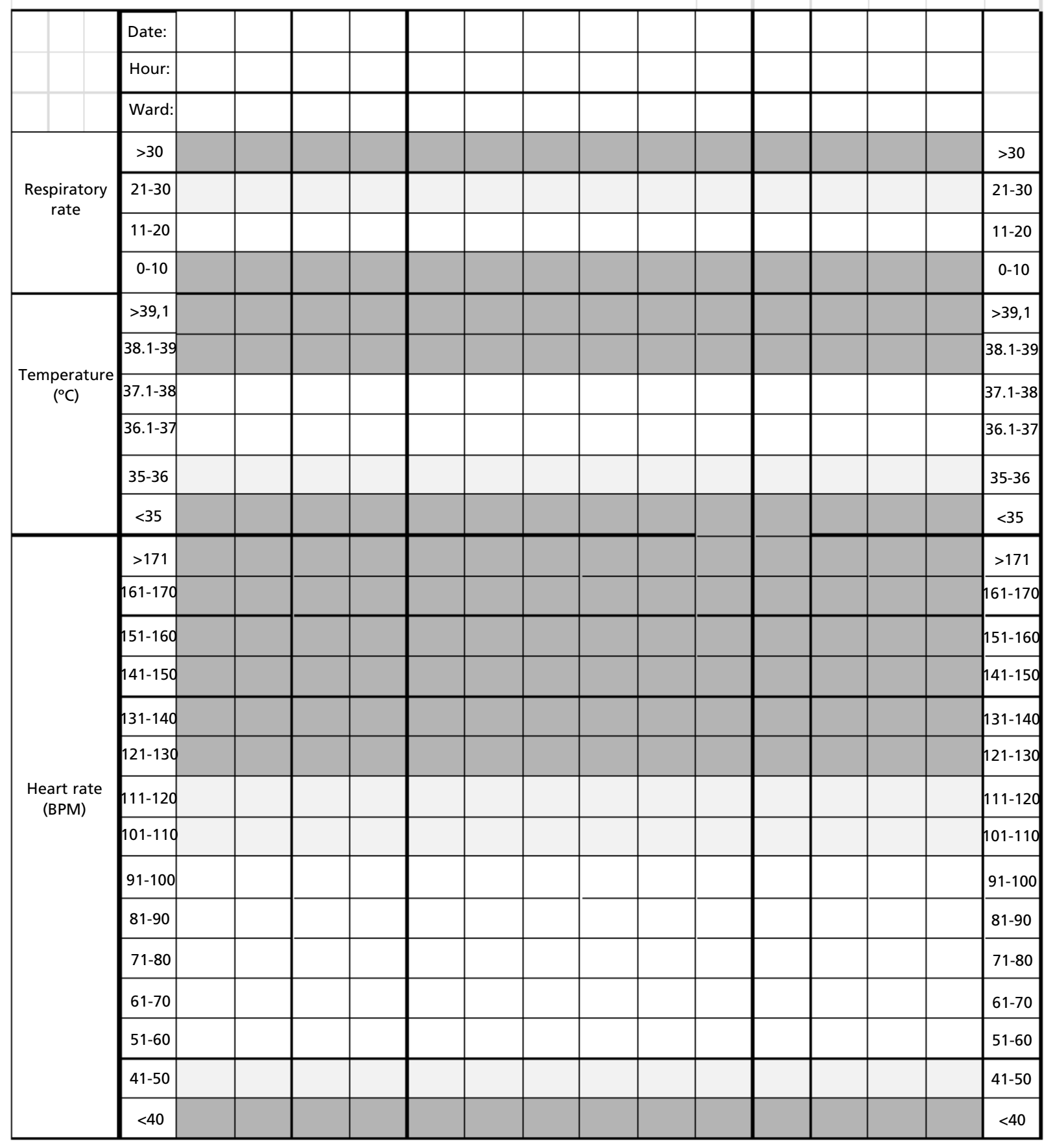


Figure 2

MEOWS graphic chart.

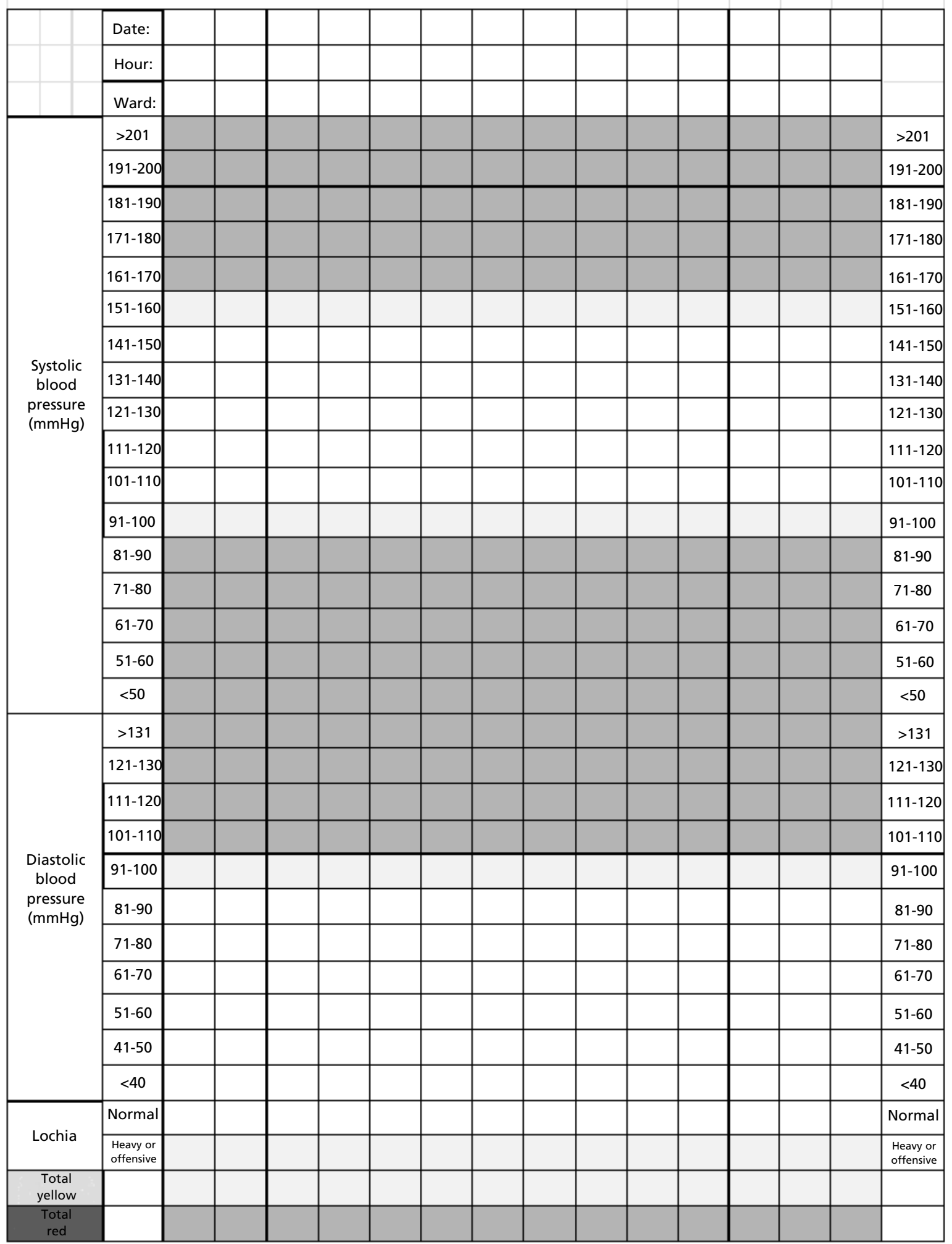




\begin{tabular}{|c|c|c|}
\hline Characteristics & $\mathbf{N}$ & $\%$ \\
\hline \multicolumn{3}{|l|}{ Maternal age (years) } \\
\hline$<20$ & 149 & 21.1 \\
\hline $20-34$ & 459 & 65.1 \\
\hline$\geq 35$ & 97 & 13.8 \\
\hline \multicolumn{3}{|l|}{ Skin color/ethnicity a } \\
\hline White & 138 & 23.0 \\
\hline Black & 56 & 9.3 \\
\hline Yellow & 13 & 2.2 \\
\hline Mixed & 391 & 65.2 \\
\hline Indigenous & 2 & 0.3 \\
\hline \multicolumn{3}{|l|}{ Education level b (years of schooling) } \\
\hline None & 6 & 1.0 \\
\hline $1-3$ & 18 & 3.1 \\
\hline $4-7$ & 156 & 26.4 \\
\hline $8-11$ & 258 & 43.7 \\
\hline$\geq 12$ & 151 & 25.6 \\
\hline Unknown & 1 & 0.2 \\
\hline \multicolumn{3}{|l|}{ Marital status c } \\
\hline Single & 205 & 33.5 \\
\hline Married/in a stable union & 401 & 65.7 \\
\hline Widowed & 0 & - \\
\hline Divorced & 5 & 0.8 \\
\hline \multicolumn{3}{|l|}{ Employment status $d$} \\
\hline Homemaker & 317 & 55.2 \\
\hline Paid employment & 212 & 37.0 \\
\hline Student & 45 & 7.8 \\
\hline
\end{tabular}

a Data available for 600 cases; b data available for 590 cases; c data available for 611 cases; d data available for 574 cases.

$19.0 \pm 1.6$ breaths/minute (range 13-28 breaths/minute). Median temperature was $36.4 \pm$ $0.5 \mathrm{oC}$ (range $34.3-38.8^{\circ} \mathrm{C}$ ). Lochia was described as normal in all cases.

Triggers were found in $49.8 \%$ patients $(n=351)$; however, in only three cases $(0.82 \%)$ a physician was called to see the patient (Table 3 ). In the three cases in which the physician was called, the time between calling the physician and receiving medical care was no longer than five minutes. In relation to the number of triggers per patient, $26.8 \%$ of the patients had more than one red alert and $67.0 \%$ had more than two yellow alerts during hospitalization. Taking only red alerts for systolic or diastolic blood pressure into consideration, this trigger was found to be present in $19 \%$ of the patients. There were no cases of maternal near miss or death in this study.

In $33 \%$ of the cases, prescribed "as needed" medication was administered four or more times per patient with analgesics and antihypertensives being the most frequent administered drugs $(66.0 \%$ and
$31.2 \%$, respectively). In almost $40 \%$ of the cases there were no registration of signs and/or symptoms on the medical records that led to the administration of prescribed "as needed" medication.

\section{Discussion}

Retrospective application of MEOWS graphic chart showed that a significant number of patients presented triggers in which were unrecognized by the nursing team in $99.2 \%$ of cases. Despite the high rate of triggers, no adverse maternal outcomes (near miss or death) occurred in this sample. The high frequency of triggers could be justified by the fact that this sample was consisted predominantly of high-risk pregnant women, particularly hypertensive women.

In the present sample, $83.3 \%$ of the patients were classified as high obstetric risk, with $49.8 \%$ of them presenting abnormalities in the physiological parameters, as shown by the identification of MEOWS 
Table 2

\begin{tabular}{|c|c|c|}
\hline Characteristics & $\mathbf{N}$ & $\%$ \\
\hline \multicolumn{3}{|l|}{ Number of pregnancies a } \\
\hline 1 & 297 & 42.4 \\
\hline 2 & 166 & 23.7 \\
\hline 3 & 107 & 15.3 \\
\hline$\geq 4$ & 130 & 18.6 \\
\hline \multicolumn{3}{|l|}{ Gestational age b (weeks) } \\
\hline$<37$ & 232 & 33.8 \\
\hline $37-41$ & 450 & 65.5 \\
\hline$\geq 42$ & 5 & 0.7 \\
\hline \multicolumn{3}{|l|}{ Parity a } \\
\hline 0 child & 4 & 0.6 \\
\hline 1 child & 331 & 47.3 \\
\hline 2 children & 184 & 26.3 \\
\hline 3 children & 97 & 13.8 \\
\hline$\geq 4$ children & 84 & 12.0 \\
\hline \multicolumn{3}{|l|}{ Classification of pregnancy risk } \\
\hline Low & 118 & 16.7 \\
\hline High & 587 & 83.3 \\
\hline \multicolumn{3}{|l|}{ Clinical comorbidities c } \\
\hline No comorbidities & 513 & 74.9 \\
\hline Hypertension & 67 & 9.8 \\
\hline Heart disease & 18 & 2.6 \\
\hline HIV/ Acquired immunodeficiency syndrome (AIDS) & 17 & 2.5 \\
\hline Other comorbidities & 70 & 10.2 \\
\hline \multicolumn{3}{|l|}{ Form of childbirth } \\
\hline Vaginal & 396 & 56.2 \\
\hline Cesarean & 297 & 42.1 \\
\hline Curettage & 6 & 0.8 \\
\hline Forceps & 4 & 0.6 \\
\hline Exploratory laparotomy & 2 & 0.3 \\
\hline
\end{tabular}

a Data available for 700 cases; b data available for 687 cases; c show three most frequent comorbidities of 685 data available.

triggers. This finding differs from the results reported from a study conducted to validate MEOWS in England. In that study, 673 patients were admitted to a tertiary hospital between 20 weeks of pregnancy and 6 weeks postpartum, with triggers being found in $30 \%$ of these patients. ${ }^{9}$ Furthermore, the patients in whom triggers were identified had a greater risk of developing morbidities and of being submitted to emergency surgery compared to the group in which no triggers were detected. Additionally, hospitalization time tended to be longer. ${ }^{9}$ In the present study, the fact that $83.3 \%$ of the cases were considered high-risk may justify the high frequency of triggers and longer hospital stay.

Indeed, one-third of the women for whom red alerts were found, $10 \%$ presented between two and eleven alerts during hospitalization. In this sample, hypertension was responsible for almost $20 \%$ of all triggers and this result may indicate that the blood pressure levels may require modification to when used in a referral hospital for high-risk patients,.

The importance of hypertension in this sample is highlighted in the fact that $50 \%$ of the patients had some form of hypertension, with severe preeclampsia and superimposed preeclampsia being responsible for $23 \%$ of the cases. The highest systolic and diastolic pressure levels found (200 and $120 \mathrm{mmHg}$, respectively) emphasize the severity of these hypertensive syndromes. The present data suggest that these levels should be reevaluated in further researches.

Despite the large number of triggers, these 
Table 3

\begin{tabular}{|c|c|c|}
\hline Characteristics & $\mathbf{N}$ & $\%$ \\
\hline \multicolumn{3}{|l|}{ Trigger } \\
\hline Yes & 351 & 49.8 \\
\hline No & 354 & 50.2 \\
\hline \multicolumn{3}{|l|}{ Trigger generated to call for medical care } \\
\hline Yes & 3 & 0.8 \\
\hline No & 361 & 99.2 \\
\hline \multicolumn{3}{|l|}{ Temperature a } \\
\hline Normal $-36.1-38^{\circ} \mathrm{C}$ & 491 & 72.4 \\
\hline Yellow alerts $-35-36^{\circ} \mathrm{C}$ & 180 & 26.5 \\
\hline Red alerts $-<35$ or $\geq 38.1^{\circ} \mathrm{C}$ & 7 & 1.1 \\
\hline \multicolumn{3}{|l|}{ Respiratory rate b } \\
\hline Normal - 11 - 20 ipm & 432 & 90.1 \\
\hline Yellow alerts - $21-30 \mathrm{ipm}$ & 43 & 9.9 \\
\hline Red alerts $-0-10$ or $>30 \mathrm{ipm}$ & 0 & - \\
\hline \multicolumn{3}{|l|}{ Heart rate $c$} \\
\hline Normal - $51-100$ bpm & 422 & 94.8 \\
\hline Yellow alerts - $41-50$ or $101-120$ bpm & 20 & 4.5 \\
\hline Red alerts $-<40$ or $\geq 121 \mathrm{bpm}$ & 3 & 0.7 \\
\hline \multicolumn{3}{|l|}{ Systolic blood pressure d } \\
\hline Normal - $101-150 \mathrm{mmHg}$ & 483 & 69.2 \\
\hline Yellow alerts - $91-100$ or $151-160 \mathrm{mmHg}$ & 165 & 23.6 \\
\hline Red alerts $-<90$ or $\geq 161 \mathrm{mmHg}$ & 50 & 7.2 \\
\hline \multicolumn{3}{|l|}{ Diastolic blood pressure $d$} \\
\hline Normal - $40-90 \mathrm{mmHg}$ & 627 & 89.8 \\
\hline Yellow alerts - $91-100 \mathrm{mmHg}$ & 56 & 8.0 \\
\hline Red alerts $-\geq 101 \mathrm{mmHg}$ & 15 & 2.2 \\
\hline \multicolumn{3}{|l|}{ Lochia e } \\
\hline Normal & 651 & 100.0 \\
\hline Yellow alerts - Increased / with odor & 0 & - \\
\hline
\end{tabular}

a Data available for 678 cases; b data available for 475 cases; c data available for 445 cases; d data available for 698 cases; e data available.

results show that the nursing team only requested medical evaluation for three patients $(0.8 \%)$. According to MEOWS recommendations, a physician should evaluate the patient in all the cases when the triggers are present. 9 This difference could be attributed to the fact that the instrument has not yet been adopted as a part of the nursing care routine at this hospital.

MEOWS was developed to provide a specific early warning system for the obstetric population, identifying patients at risk on severe obstetric complications and permit intervention in being made at an early stage. 9,19 Nevertheless, despite the large number of triggers found, there were no cases of maternal near miss or death. We believe that adverse outcomes were not detected because the sample size was too small to show these outcomes. Therefore, it is important to reflect on whether the adoption of this instrument in its current form is viable, since if every trigger were to result in a call for a medical team, perhaps this could overload their work. ${ }^{20}$

Studies have raised concerns regarding to the alert frequency, which should be low in order to prevent "warning fatigue". ${ }^{20}$ In a study conducted in the United States using a warning system designed for the obstetric population, calls for the medical team were prompted if two conditions were present: the presence of two yellow triggers or one red trigger, if the trigger remained in place for more than 20 minutes. ${ }^{21}$ In that study, which included almost 120,000 childbirths, the trigger frequency was low, and only 1 was present in every 50 patients presenting positive tracking results. 21 The use of a warning system associated with a predefined time of 
this alert could be an alternative to increase the positive predictive value of the early obstetric warning system and avoid an exaggerated number of triggers that could discredit the use of the instrument. It is also important to adjust the levels of alerts considering each marker, according to the population's profile in order to avoid a large number of falsepositive alerts.

Another point to be assessed is the speed in which the physician is called once the trigger is activated, and the time the physician takes to assist that call. The puerperal were evaluated by the physician, and were verified by the time that was approximately five minutes between the trigger and the call for medical care, and the same timing was verified between the trigger and the medical care. These findings are in agreement with the recommendations of various early warning systems, 18,19,22 where rapid response in providing medical care is the key to avoid clinical decompensation.

Studies have reported a sensitivity of $89 \%$ for MEOWS, ${ }^{9}$ higher than the $43 \%$ found for the nonobstetric early warning systems commonly used in the adult population. 22 This is probably due to the fact that the primary endpoint with MEOWS is morbidity, unlike the systems used for the nonobstetric adult population in which the endpoints are generally death or admission to an intensive care unit. 9 The literature also shows that the specificity of MEOWS for predicting morbidity is $79 \%$, comparable to the early warning systems designed for the non-obstetric adult population with a positive predictive value of $39 \%$ and $98 \%$ of a negative predictive value. 9

Information regarding lochia forms an important part of the puerperal clinical evaluation and can reveal signs of puerperal infection, which is an important cause of mortality in Brazil and worldwide. ${ }^{23,24}$ Patients with lochia in the present study were described as normal in $100 \%$ of the cases, which probably is an indication that this clinical sign was not adequately evaluated or that the professionals paid little attention to it. On the other hand, it should be emphasized that the unit to which these patients were admitted receives patients from the postpartum unit after the first two hours of childbirth (the most critical period for hemorrhagic complications) or from the obstetric intensive care unit after their condition has stabilized. These specific criteria at this institution regarding to transfer to the unit may have selected more stable patients from a hemorrhagic point of view and perhaps for this reason the type of complication was not identified.

Although it is not part of MEOWS checklist, this study also evaluated the extent to which prescribed "as needed" medication was administered and identified that the fact occurred in $23 \%$ of the patients. In one-third of the cases, analgesics and antihypertensives were administered four or more times per patient with a frequency of $66.0 \%$ and $31.2 \%$, respectively. In our service, which MEOWS has not been yet implemented, a hypertension puerperal (systolic blood pressure $\geq 160 \mathrm{mmHg}$ or diastolic blood pressure $\geq 110 \mathrm{mmHg}$ ) was administered antihypertensives for very high blood pressure episodes without the need to call a physician.

Some obstacles need to be overcome before early warning systems such as MEOWS can be incorporated into practice. ${ }^{20}$ A continued education program needs to be offered to professionals involved in obstetric care so that they understand the significance of abnormalities in vital signs and what these changes may mean. MEOWS trigger parameters can lead to the detection of unrecognized conditions: postpartum hemorrhage (which could be suspected from the presence of hypotension and tachycardia), sepsis (fever, hypotension, tachycardia, hypoxia), and venous thromboembolism (tachycardia, tachypnea, hypoxia). ${ }^{19}$ A study conducted with nurses in Norway showed that early warning systems were able to provide greater volume of information on the evolution of maternal signs and symptoms, as well as improving the work of the hospital team. 25

Another issue that needs to be overcome before the tool can be adopted is the need to adjust its limits according to the population to be evaluated. It would be important to perform accurate studies with appropriate sample size assessing other cut-off points for each parameter.

A limitation of this study that needs to be mentioned is the fact that the design is observational, and the evaluation was limited by the availability of the data in the medical records. The sample included was insufficient to evaluate whether these events were associated with adverse outcomes. Another limitation is that the sample was mostly composed by high-risk women, a fact that may have raised the incidence of the triggers.

On the other hand, according to the best of our knowledge, this is the first study to apply the early warning system in a low-income country and using a sample of patients from a high-risk hospital. It is in our belief that the information on the performance of this tool under these circumstances is vital in order to further refine it, enabling its use in different settings. The application of this tool would result in better care to the extent that critical situations would 
be recognized and corrected quickly by avoiding unfavorable outcomes.

\section{Authors' contribution}

Schuler L, Coutinho IC, Melo BCP and Katz L designed the initial project, which was reviewed by Katz L and Coutinho IC. Schuler L was responsible for the data collection. Schuler L and Katz L performed the statistical analysis. Schuler L wrote the draft of the article, which was reviewed by
Coutinho IC, Katz L and Melo BCP. All the authors read and approved the final version of the manuscript.

\section{References}

1. WHO, UNICEF, UNFPA, the World Bank, the United Nations Population Division. Trends in maternal mortality: 1990 to 2013. Estimates by WHO, UNICEF, UNFPA, the World Bank, and the United Nations Population Division. Geneva: World Health Organization; 2014.

2. Firoz T, Chou D, von Dadelszen P, Agrawal P, Vanderkruik R, Tunçalp O; Maternal Morbidity Working Group. Measuring maternal health: focus on maternal morbidity. Bull World Health Organ. 2013; 91 (10): 794-6.

3. Souza JP, Cecatti JG, Faundes A, Morais SS, Villar J, Carroli G, Gulmezoglu M, Wojdyla D, Zavaleta N, Donner A, Velazco A, Bataglia V, Valladares E, Kublickas M, Acosta A. Maternal near miss and maternal death in the World Health Organization's 2005 global survey on maternal and perinatal health. Bull World Health Organ. 2010; 88 (2): 113-9.

4. Souza JP, Cecatti JG, Parpinelli MA, Sousa MH, Serruya SJ. [Systematic review of near miss maternal morbidity].Cad Saúde Pública. 2006; 22 (2): 255-64.

5. Say L, Souza JP, Pattinson RC; WHO working group on Maternal Mortality and Morbidity classifications. Maternal near miss - towards a standard tool for monitoring quality of maternal health care. Best Pract Res Clin Obstet Gynaecol. 2009; 23 (3): 287-96

6. Kyriacos U, Jelsma J, James M, Jordan S. Monitoring vital signs: development of a modified early warning scoring (MEWS) system for general wards in a developing country. PLoS One. 2014; 9 (1): e87073.

7. Kyriacos U, Jelsma J, Jordan S. Record review to explore the adequacy of post-operative vital signs monitoring using a local modified early warning score (Mews) chart to evaluate outcomes. PLoS One. 2014; 9 (1): e87320.

8. Morgan RJ, Williams F, Wright MM. An early warning scoring system for detecting developing critical illness. Clinical Intensive Care. 1997;8:100.

9. Singh S, McGlennan A, England A, Simons R. A validation study of the CEMACH recommended modified early obstetric warning system (MEOWS). Anaesthesia. 2012; 67 (1): $12-8$.

10. Lewis G. The Confidential Enquiry into Maternal and Child Health (CEMACH). Saving mothers' lives: reviewing

maternal deaths to make motherhood safer: 2003-2005. The Seventh Report on Confidential Enquiries into Maternal Deaths in the United Kingdom. London: CEMACH; 2007.

11. Breslin A, McGlennan A. The Royal Free Hospital NHS Trust Maternity Clinical Guidelines. MEOWS Guidance in Maternity. London: Royal Free Hospital; 2009.

12. Wilkinson H; Trustees and Medical Advisers. Saving mothers' lives. Reviewing maternal deaths to make motherhood safer: 2006-2008. BJOG. 2011; 118 (11): 1402-3.

13. Cantwell R, Clutton-Brock T, Cooper G, Dawson A, Drife J, Garrod D, Harper A, Hulbert D, Lucas S, McClure J, Millward-Sadler H,Neilson J, Nelson-Piercy C, Norman J, O'Herlihy C, Oates M, Shakespeare J, de Swiet M, Williamson C, Beale V, Knight M, Lennox C, Miller A, Parmar D, Rogers J, Springett A. Saving mothers' lives: reviewing maternal deaths to make motherhood safer: 2006-2008. The Eighth Report of the Confidential Enquiries into Maternal Deaths in the United Kingdom. BJOG. 2011; 118 (Suppl. 1): 1-203.

14. Farquhar C, Sadler L, Masson V, Bohm G, Haslam A. Beyond the numbers: classifying contributory factors and potentially avoidable maternal deaths in New Zealand, 2006-2009. Am J Obstet Gynecol. 2011;205(4):331.e1-8.

15. Saucedo M, Deneux-Tharaux C, Bouvier-Colle MH; French National Experts Committee on Maternal Mortality. Ten years of confidential inquiries into maternal deaths in France, 1998-2007. Obstet Gynecol. 2013; 122 (4): 752-60.

16. American College of Obstetricians and Gynecologists Committee on Patient Safety and Quality Improvement. Committee opinion no. 590: preparing for clinical emergencies in obstetrics and gynecology. Obstet Gynecol. 2014; 123 (3): $722-5$

17. The Joint Commission. Sentinel Event Alert, Issue 44: Preventing Maternal Death. January 26, 2010.

18. Mhyre JM, D'Oria R, Hameed AB, Lappen JR, Holley SL, Hunter SK, Jones RL, King JC, D'Alton ME. The maternal early warning criteria: a proposal from the national partnership for maternal safety. J Obstet Gynecol Neonatal Nurs. 2014; 43 (6): 771-9.

19. FriedmanAM. Maternal early warning systems. Obstet Gynecol Clin North Am. 2015; 42 (2): 289-98. 
20. Shields LE, Wiesner S, Klein C, Pelletreau B, Hedriana HL. Use of Maternal Early Warning Trigger tool reduces maternal morbidity. Am J Obstet Gynecol. 2016;214(4):527.e1-6.

21. Hedriana HL, Wiesner S, Downs BG, Pelletreau B, Shields LE. Baseline assessment of a hospital-specific early warning trigger system for reducing maternal morbidity. Int J Gynaecol Obstet. 2016; 132 (3): 337-41.

22. Gao H, McDonnell A, Harrison DA, Moore T, Adam S, Daly K, Esmonde L, Goldhill DR, Parry GJ, Rashidian A Subbe CP, Harvey S.Systematic review and evaluation of physiological track and trigger warning systems for identifying at-risk patients on the ward. Intensive Care Med 2007; 33 (4): 667-79.

Received on April 5, 2018

Final version presented on May 21, 2019

Approved on June 4, 2019
23. Objetivos de Desenvolvimento do Milênio. Relatório Nacional de Acompanhamento. Brasília: Ipea; 2014.

24. Say L, Chou D, Gemmill A, Tunçalp Ö, Moller AB, Daniels J, Gülmezoglu AM, Temmerman M, Alkema L. Global causes of maternal death: a WHO systematic analysis. Lancet Glob Health. 2014; 2 (6): e323-33.

25. Stafseth SK, Grønbeck S, Lien T, Randen I, Lerdal A. The experiences of nurses implementing the Modified Early Warning Score and a 24-hour on-call Mobile Intensive Care Nurse: an exploratory study. Intensive Crit Care Nurs. 2016; 34: 25-33 